\section{Recovery of Unengorged Larval Trombiculid Mites (Acarina) from Ground Holes}

Previously it was found possible to identify the natural habitats of a limited number of species of larval trombiculid mites (chiggers) in Malaysia by recovering them from the ground on black 'Formica' plates'. In such habitats as were found, it was possible to observe with the naked eye chiggers both singly and in clusters. Only two species of chiggers have so far been subjected to intensive investigation using this recovery technique and both wero vectors of scrub typhus, Leptotrombidium (Leptotrombidium) deliense (Walch, 1922) and L. (L.) akamushi (Brumpt, 1910). In the few localities studied by this means, the former was found in lalang grassland (Imperata cylindrica) and the latter on ground leaf-litter of secondary forest galleries ${ }^{2}$. In the course of current investigations of scrub typhus in the primary and secondary forests of Malaysia, we have collected a number of species of larval trombiculids-previously found only on small forest mammals-by insertion of a flat strip of black 'Formica' into ground holes.

The ground holes were probably formed as a result of activities of large animals, although some may have resulted from weathering. They are frequently to be found on the sides of escarpments or small mounds, among the roots of trees, and often in natural rock and earth fissures. In general, however, the holes which are infested occur in shaded arcas; their interiors are cool, damp and usually free of litter or debris. Chiggers have been recovered from wide, low crevices on sloping ground and from holes which are as shallow as 4 in., and which vary in diameter from 2 in. to 6 in. Although the mites have generally been recovered from within 1-14 in. of the mouth of the hole, the maximum depth at which they are found has not yet been determined.

About half the holes which we have examined have yielded larval mites. The number of larvae recovered from a single hole may vary from one to more than two hundred. It was found that chiggers could best be recovered by simply inserting the 'Formica' plate into the hole for a second or so; its presence somehow stimulated the mites to drop on to it from the roof of the hole (where they were most frequently situated). (An investigation of the stimulus involved here is at present being carried out; so also is a search for nymphal and adult forms and the identity of their usual hosts.)

The specimons of $L$. $(L$.$) deliense recovered from holes$ are white whereas those of $L$. (L.) deliense collected in abundance from established ground surface habitats are orange in colour. Indeed all but two of the twenty-five collected from holes were whitish in colour; the exceptions were $W$. oudemansi and E. wichmanni. The relationship between colour and habitat is also the subject of active investigations.

So far, twenty-five larval species, including several which have not previously been described, have been recovered from ground holes (Table 1). Thirteen of the twenty-five belong to the genus Gahrliepia.

Previous attempts to grow nine species of Gahrliepia under ambient laboratory conditions were not successful. Fourteen species of chiggers collected have now been successfully bred under conditions simulating the natural micro-environmont ${ }^{3}$; seven of these had been recovered from open fields and plantations or from rodents trapped there, while the others were from more heterogeneous habitats. A knowledge of temperature, humidity and food requirements such as could be derived from further studies of these newly recognized habitats should enable us to breed gahrliepiines and other forest chiggers in the laboratory. Because of the relative ease with which these mites can be recovered, investigations of the bionomies of a large number of Malaysian mites and their possible role in the transmission of scrub typhus and other enzootic infections can now be put into operation.
Table 1. Species Recovered From Grodnd Holes

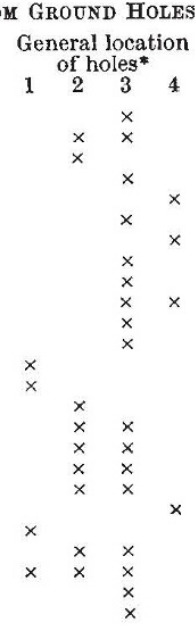

* (1) Primary forest, $>5,000 \mathrm{ft}$.; twenty holes examined; (2) primary forest, $<3,000 \mathrm{ft}$; ; sixty holes examined; (3) secondary forest, $<3,000 \mathrm{ft}$.;
one hundred holes examined; (4) palm island in rice field; twenty holes examined.

This work was supported in part by a research grant (to W. D. K.) from the Office of International Research.

$$
\begin{aligned}
& \text { W. D. KUNDIN* } \\
& \text { M. NADCHATRAM } \\
& \text { RoBERT W. UPHAM, JUN. } † \\
& \text { GaRRISON RapMUND } †
\end{aligned}
$$

Institute for Medical Research,

Kuala Lumpur, Malaysia.

* From the University of California International Center for Medical Research and Training (Hooper Foundation).

$\uparrow$ From the U.S. Army Medical Research Unit.

${ }^{1}$ Hubert, A. A., and Baker, H. J., Amer. J. Hyg., 78, 131 (1963).

${ }^{2}$ Gentry, J. W., Cheng, S. Y., and Phang, O. W., Amer. J. Hyg., 78, 181 (1063).

8 Nadchatram, M., and Audy, J. R. (unpublished results).

\section{Antagonistic Interaction between Schistosoma mansoni Sporocysts and Echinostome Rediae in the Snail Australorbis glabratus}

IT has recently been shown that antagonistic interaction takes place when schistosome, strigeid or plagiorchiid sporocysts occur together with certain echinostome rediae in the same snail ${ }^{1}$. This interaction results in the total elimination of the first three groups of parasites. This communication discusses the antagonistic interaction between sporocysts of Schistosoma mansoni Sambon and rediae of an unidentified Echinostoma species in the snail Australorbis glabratus (Say).

The Echinostoma species was isolated from an $A$. glabratus collected near Recife, Brazil. It is morphologically close to $E$. audyi, but its exact identity is still under study. Cercariae of this echinostome encyst in various freshwater snails, including $A$. glabratus, and these cysts develop into adults when fed to chicks and ducklings. The strain of $S$. mansoni and the experimental snails were obtained from the National Institutes of Health, Bethesda, Maryland. Only albino snails were used because it is then easier to observe rediae and sporocysts and their interaction through the shells.

The Echinostoma sporocysts develop in the ventricle. cavity of the snail, rediae mainly in the ovotestis but also. in the liver, lung, kidney and mantle edge. Daughtersporocysts of $S$. mansoni migrate from the anterior of the snail, where the mother sporocyst develops, to the visceral mass. Development of both species of parasites is apparently normal so long as they occupy different areas in the snail. Observations made on thirty-six snails with double infection have shown that wherever schistosome daughter sporocysts and echinostome rediae are 